\title{
BACTERIAL ENDOCARDITIS COMPLICATING SEPTICAEMIA IN AN INFANT
}

\author{
BY \\ IAN C. LEWIS \\ Royal Hospital for Sick Children, Edinburgh \\ (RECEIVED FOR PUBLICATION NOVEMBER 9, 1953)
}

Septicaemia in the first few months of life is still unfortunately a relatively common condition, but the introduction of antibiotics has altered the prognosis dramatically. However, certain factors, such as a failure to reach a diagnosis, or an unusually virulent or resistant organism, may result in death.

Bacterial endocarditis is a rare complication of septicaemia in infants, and the existing descriptions are, in general, unsatisfactory because of insufficient bacteriological and pathological detail (Morison, 1952).

Sansby and Larson (1930) gave several references from the German literature of between 50 and 70 years ago and they also collected more recent reports on cases of bacterial endocarditis occurring in infants, but most of these were incomplete. Their own case was supported only by macroscopic descriptions of the heart and the causative organism was not named.

Since this paper, D'Ewart (1931) recorded a case of a 13-day-old infant with a staphylococcal septicaemia. The heart lesion was on the posterior wall of the right ventricle near the pulmonary valve. Brandes (1933) reported the occurrence of gonococcal tricuspid endocarditis in a 10-day-old infant. Plaut and Sharnoff (1935) and Plaut (1939) added two further cases but in neither was an organism found. The first of their cases occurred in a premature foetus, a small vegetation being discovered on a mitral valve cusp. In the second case, a day-old infant with a tricuspid valvular lesion, there were additional factors such as two possibly infected ante-mortem venous thrombi and a subarachnoid haemorrhage.

In an interesting paper Wolff (1940) reviewed the continental, American and British literature before giving details of two infants aged 3 months and $3 \frac{1}{2}$ months, diagnosed on clinical grounds as suffering from bacterial endocarditis. Both survived the acute illness, which was attributed to a staphylococcal skin infection, only to be left with permanent cardiac damage.

Since the advent of the antibiotics no further case reports have been traced, and, in view of this rather scanty and often unsatisfactory literature, the following case is recorded.

\section{Case Report}

C.G., a boy, the second child of healthy, unrelated parents, was born by a low forceps delivery at term in an Edinburgh nursing home on August 29, 1952. His birth weight was $8 \mathrm{lb} .3 \mathrm{oz}$. He made normal progress until his ninth day of life when he became anorexic, listless and irritable. His condition deteriorated, and on September 9 he was admitted to the Royal Hospital for Sick Children, Edinburgh, aged 11 days.

When examined on admission, he was a toxic-looking, jaundiced infant. His state of hydration was poor and his tongue was flecked with bile-stained vomitus. The abdomen was distended and an area of induration surrounded an infected umbilical stump. The liver and spleen each extended about one inch below the costal margins. No other abnormality was found on clinical examination.

Table 1 and Fig. 1 give details of the temperature, body weight, number of stools and vomits, haematology and examination of urine.

TABLE 1

DETAILS OF BLOOD AND URINE EXAMINATIONS

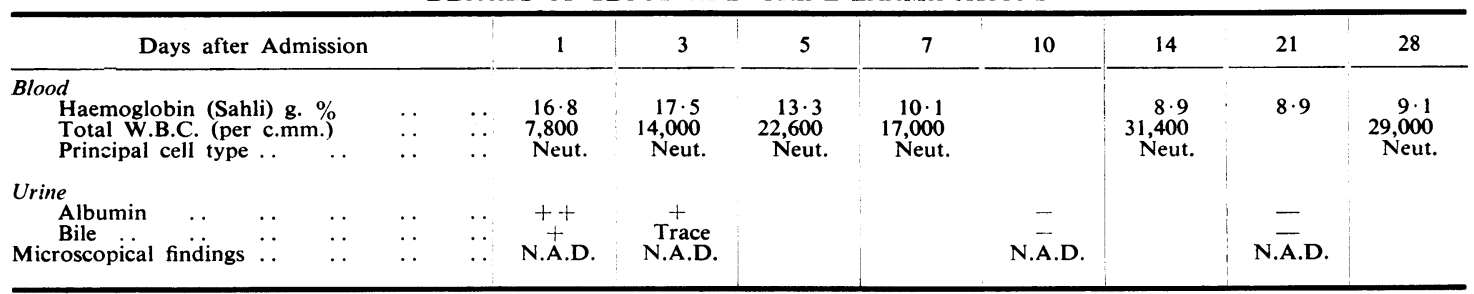


Mans: C. $G$.

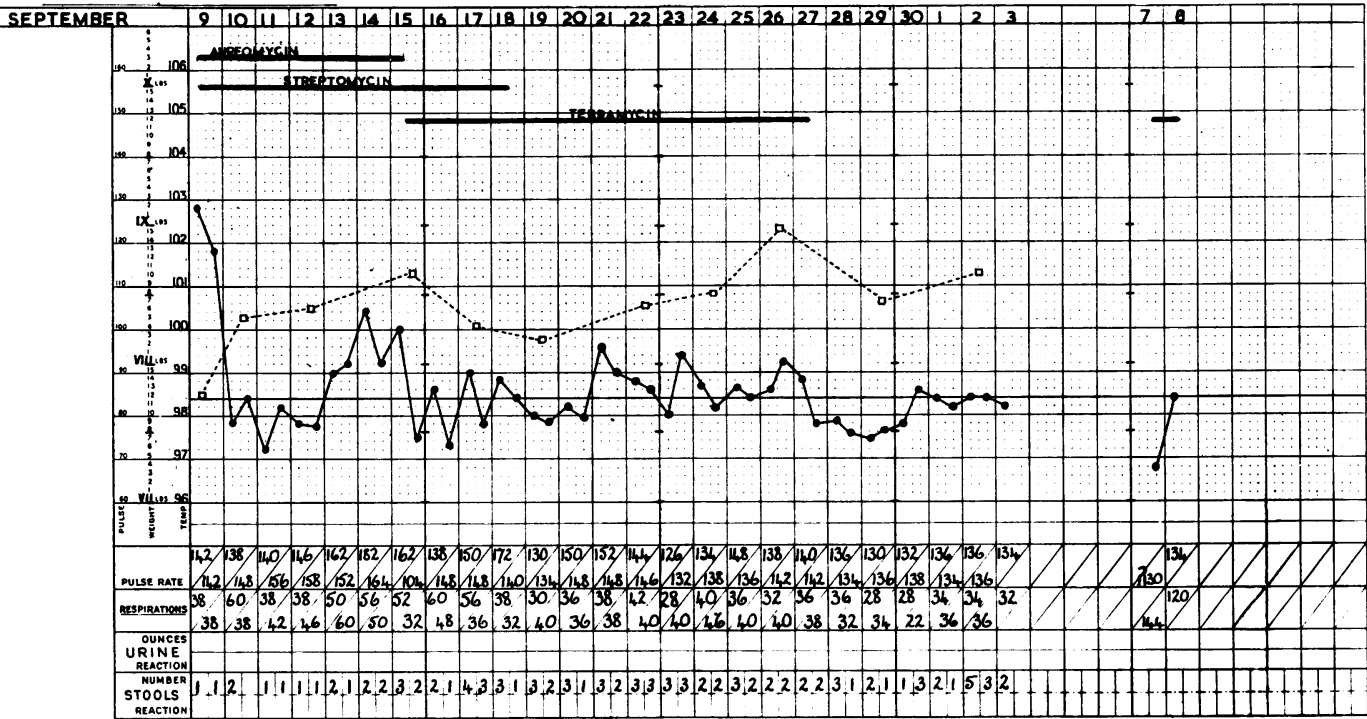

Fig. 1.

Therapy was begun immediately a clinical diagnosis of septicaemia had been made. He was given streptomycin, $200 \mathrm{mg}$. twice daily intramuscularly, and aureomycin, $100 \mathrm{mg}$. six hourly orally.

The umbilical discharge was swabbed and yielded a growth principally of coagulase-positive Staphylococcus aureus.

During the first two days in hospital, despite the disappearance of fever, his condition deteriorated, oedema of the legs and sacrum developed, and, in addition to deepening jaundice. an extensive purpuric rash appeared on the trunk and limbs. Thereafter both the jaundice and purpura slowly faded although the oedema increased. Six days after admission he was free of jaundice but the oedema remained. As he was still feverish, terramycin, $50 \mathrm{mg}$. six hourly orally, was substituted for aureomycin. The infant began to improve steadily and the oedema slowly disappeared. The liver and spleen became smaller. He was discharged home on October 3, 24 days after admission, apparently in good health.

For two days he remained well, but then he began to vomit and became dyspnoeic during his feeds. He was anorexic. A systolic murmur was present over the whole of the praecordium but it was maximal at the apex. The apex beat was rather diffuse and it was in the fifth interspace about half an inch outside the mid-clavicular line. The infant was readmitted in the evening of October 7. In addition to the cardiac signs, the liver extended for about 2 in. below the costal margin and the spleen was again easily palpable. A blood culture taken on admission later proved to be sterile. Oxygen therapy and terramycin were given but the infant died suddenly next morning.
A post-mortem examination was performed three hours later.

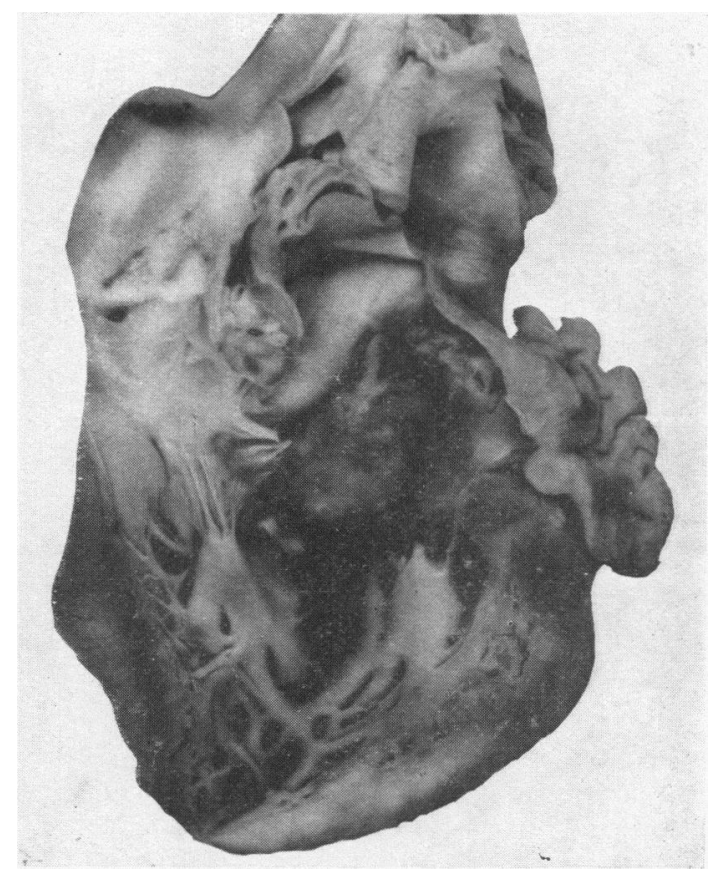

FIG. 2.-Section through the left ventricle showing the large vegetation on the cusp of the mitral valve. 
Abstract OF POST-Mortem RePort, Both pleural sacs contained an increased quantity of fluid. The lungs were firm and oedematous. The heart was increased to about one and a half times the usual size due to hypertrophy and dilatation of the right ventricle, and by dilatation of the left ventricle. Firmly adherent to the posterior cusp of the mitral valve and projecting into the left atrium there was a large elongated, firm mass of thrombus, about $2 \mathrm{~cm}$. in length (Fig. 2). Smaller masses of thrombus were adherent to the other cusps. The cusps themselves were not obviously thickened, nor were the chordae tendineae shortened or thickened. The other valves of the heart showed no abnormality. The peritoneal sac contained an excess of clear fluid. The liver and spleen were both increased to about one and a half times the usual size, the result of a chronic venous congestion.

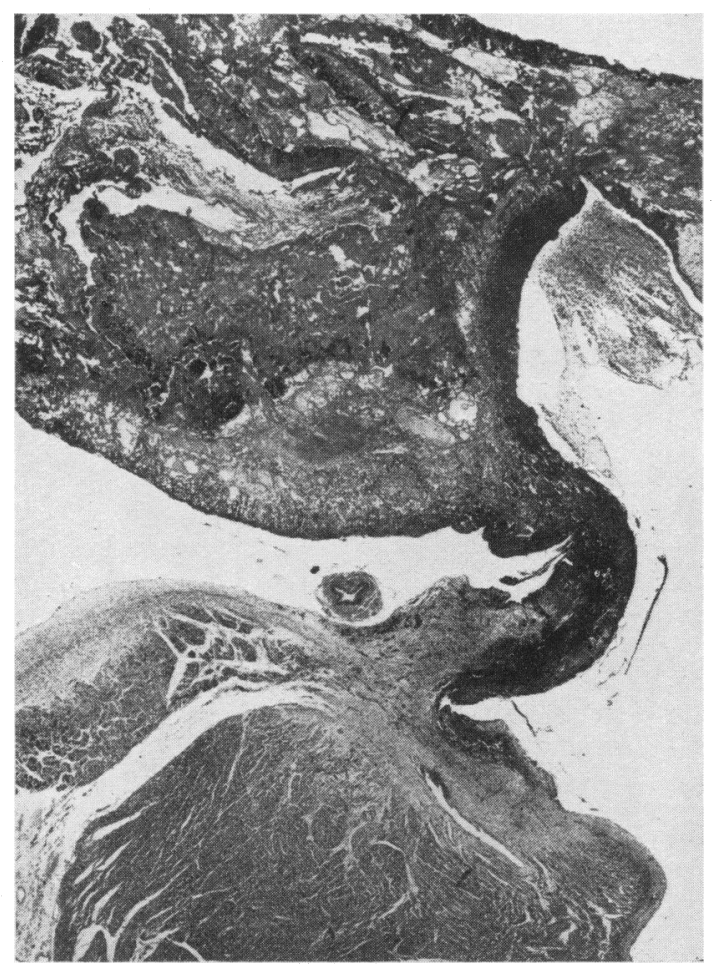

Fig. 3.-Photomicrograph showing the attachment of the thrombus to the cusp of the mitral valve.
Each kidney showed small, whitish, firm areas in the cortex, probably infarcts.

Microscopical RePORT. The lungs, liver and spleen showed the typical features of chronic congestion. In the kidneys the presence of small cortical infarcts was confirmed. Sections of the mitral valve showed the cusps to be composed of granulation tissue (Fig. 3). On the surface was a mass of thrombus into which this granulation tissue was extending. Numerous clumps of Gram-positive cocci were evident throughout the thrombotic mass. In addition to the large thrombotic mass noted at necropsy, microscopy confirmed the presence of smaller vegetations on the other cusps, and in these the histological picture was similar. The tricuspid valve showed no abnormality.

The pathologist concluded that this was a case of acute infective endocarditis, apparently altered as a result of antibiotic therapy, in which mechanical obstruction resulting from massive thrombus deposition on the mitral valve was an important factor in causing death.

\section{Comment}

This case presented initially with the characteristic signs of septicaemia. The infection appeared to be staphylococcal as this organism was grown from the umbilicus and Gram-positive cocci in clusters were seen in the section of the mitral valve vegetation.

The infant apparently responded to antibiotics and when he was discharged from hospital no cardiac abnormality was suspected. The clinical picture on his readmission four days later was that of congestive heart failure. The cause of the symptoms was only discovered at the post-mortem examination when the size and situation of the endocardial vegetation showed that there must have been intermittent obstruction of the mitral orifice.

I should like to thank Dr. D. N. Nicholson for permission to publish this case, Dr. A. D. Bain for the postmortem summary, Mr. T. C. Dodds who kindly supplied the photomicrographs, and I am also very grateful to Professor R. W. B. Ellis for his helpful criticism.

\section{REFERENCES}

Brandes, W. W. (1933). Amer. J. Dis. Child., 46, 341.

D'Ewart. J. (1931). Brit. med. J., 2. 699.

Moris, J E (1952). Foetal and Neonatal Pathology, p. 321. London.

Plaut, A. (1939). Amer. J. Path., 15, 649.
and Sharnoff, G. (1935). Arch. Path., Chicago, 20, 582.

Sansby, J. M. and Larson, L. M. (1930). Amer. J. Dis. Child., 39, 1261. Wolf,' S. (1940). Brit. J. Child. Dis., 37, 241. 